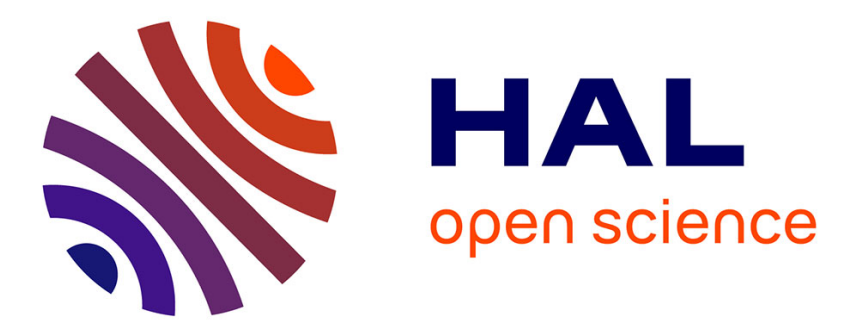

\title{
Psychological momentum during and across sports matches: Evidence for interconnected time scales.
}

Ruud J.R. den Hartigh, Paul L.C van Geert, Nico W. van Yperen, Ralf F.A Cox, Christophe Gernigon

\section{- To cite this version:}

Ruud J.R. den Hartigh, Paul L.C van Geert, Nico W. van Yperen, Ralf F.A Cox, Christophe Gernigon. Psychological momentum during and across sports matches: Evidence for interconnected time scales.. Journal of Sport and Exercise Psychology, 2016, 38 (1), pp.82-92. 10.1123/jsep.2015-0162 . hal02519559

\section{HAL Id: hal-02519559 \\ https://hal.science/hal-02519559}

Submitted on 26 Mar 2020

HAL is a multi-disciplinary open access archive for the deposit and dissemination of scientific research documents, whether they are published or not. The documents may come from teaching and research institutions in France or abroad, or from public or private research centers.
L'archive ouverte pluridisciplinaire HAL, est destinée au dépôt et à la diffusion de documents scientifiques de niveau recherche, publiés ou non, émanant des établissements d'enseignement et de recherche français ou étrangers, des laboratoires publics ou privés. 
See discussions, stats, and author profiles for this publication at: https://www.researchgate.net/publication/299453768

\section{Psychological Momentum During and Across Sports Matches: Evidence for Interconnected Time Scales}

Article in Journal of Sport \& Exercise Psychology · February 2016

DOI: 10.1123/jsep.2015-0162

CITATIONS

13

5 authors, including:

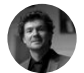

Ruud J.R. Den Hartigh

University of Groningen

45 PUBLICATIONS 312 CITATIONS

SEE PROFILE

Nico W. Van Yperen

University of Groningen

149 PUBLICATIONS 6,439 CITATIONS

SEE PROFILE

Some of the authors of this publication are also working on these related projects:

Dynamics and Variability in the process of Human-Automation Interaction View project

Project Dynamic Modeling of Action Planning View project
READS

455

Paul van geert

University of Groningen

242 PUBLICATIONS 3,948 CITATIONS

SEE PROFILE

Ralf FA Cox

University of Groningen

92 PUBLICATIONS 906 CITATIONS

SEE PROFILE 


\title{
Psychological Momentum During and Across Sports Matches: Evidence for Interconnected Time Scales
}

\author{
Ruud J. R. Den Hartigh, ${ }^{1}$ Paul L. C. Van Geert, ${ }^{1}$ Nico W. Van Yperen, ${ }^{1}$ \\ Ralf F. A. Cox ${ }^{1}$ and Christophe Gernigon ${ }^{2}$ \\ ${ }^{1}$ University of Groningen; ${ }^{2}$ University of Montpellier
}

\begin{abstract}
This study on psychological momentum (PM) in sports provides the first experimental test of an interconnection between short-term PM (during a match) and long-term PM (across a series of matches). Twentytwo competitive athletes were striving to win a prize during a rowing-ergometer tournament, consisting of manipulated races. As hypothesized, athletes who had developed long-term positive PM after two successful races were less sensitive to a negative momentum scenario in the third race, compared with athletes who had developed long-term negative PM after two unsuccessful races. More specifically, the exerted efforts, perceptions of momentum, and self-efficacy were higher for participants who had developed long-term positive PM, and their perceptions of momentum and self-efficacy decreased less rapidly. These results illustrate a typical complex dynamical systems property, namely interconnected time scales, and provide deeper insights into the dynamical nature of PM.
\end{abstract}

Keywords: attractor, complexity, dynamical systems, effort exertion, self-efficacy

Athletes, coaches, supporters, and commentators often report about periods of momentum occurring during a sports match or season (e.g., Briki, Den Hartigh, Markman, \& Gernigon, 2014; Eisler \& Spink, 1998; Iso-Ahola \& Dotson, 2014; Markman \& Guenther, 2007). The term psychological momentum (PM) refers to the psychological and behavioral changes that occur when athletes perceive that they are progressing (positive momentum) or regressing (negative momentum) in relation to their goal (Adler, 1981; Gernigon, Briki, \& Eykens, 2010; Markman \& Guenther, 2007; Vallerand, Colavecchio, \& Pelletier, 1988). Overall, previous studies on momentum in sports matches found more positive psychological states (Briki, Doron, Markman, Den Hartigh, \& Gernigon, 2014; Eisler \& Spink, 1998; Markman \& Guenther, 2007; Miller \& Weinberg, 1991; Vallerand et al., 1988) and often better performance behaviors (Den Hartigh, Gernigon, Van Yperen, Marin, \& Van Geert, 2014; Perreault, Vallerand, Montgomery, \& Provencher, 1998) for athletes who progress in relation to their goal (the victory), than those who regress or keep up with their opponent. Thus, a large body of literature shows that progression or regression

Ruud J. R. Den Hartigh, Paul L. C. Van Geert, Nico W. Van Yperen, and Ralf F. A. Cox are with the Department of Psychology, University of Groningen, The Netherlands. Christophe Gernigon is with the Department of Sport and Physical Education Sciences, University of Montpellier, France. Address author correspondence to Ruud J.R. Den Hartigh at j.r.den. hartigh@rug.nl. affects PM, both at the psychological and behavioral level (for an extensive review on PM in sports and other performance domains, see Iso-Ahola \& Dotson, 2014).

Apart from the literature on the effects of progress and regress, researchers have recently started to examine the dynamical nature of PM, that is, how it changes when progressing and regressing in relation to a desired goal (Briki, Den Hartigh, Markman, Micallef, \& Gernigon, 2013; Den Hartigh et al., 2014; Gernigon et al., 2010; for early descriptive studies on the dynamical PM process, see Adler, 1981; Adler \& Adler, 1978). According to Gernigon and colleagues, PM shows properties that are typical for complex dynamical systems (Briki et al., 2013; Briki, Den Hartigh et al., 2014; Den Hartigh et al., 2014; Gernigon et al., 2010). Simply put, a complex dynamical system is a set of interconnected components that undergoes change, and is characterized by the emergence of self-sustaining patterns (attractors), nonlinear transitions between attractors, history dependence, and interconnected time scales (Kelso, 1995; Nowak \& Vallacher, 1998; Thelen \& Smith, 1994; Van Geert, 1994). Recent studies have provided evidence for some of these dynamical properties of PM, looking at nonlinearity and history dependence in particular (Briki et al., 2013; Briki, Den Hartigh et al., 2014; Den Hartigh et al., 2014; Gernigon et al., 2010; see also next section). However, the defining property of interconnected time scales has never been empirically examined, and studying this property may provide deeper insights into the dynamical nature of PM. Therefore, we designed an experiment to test the 
development of long- and short-term PM, in particular whether the PM processes across these time scales are interconnected.

\section{Nonlinear Transitions and History Dependence of Psychological Momentum}

Indications for the emergence of PM out of the interactions between multiple components can be derived from qualitative studies, showing that several personal, environmental, and social factors in interaction shape an athlete's PM experience (e.g., Briki, Den Hartigh, Hauw, \& Gernigon, 2012; Jones \& Harwood, 2008; Moesch \& Apitzsch, 2012; Taylor \& Demick, 1994). Furthermore, experimental studies have found evidence for nonlinear transitions between positive and negative PM that are history dependent. That is, changes in PM depend on the history of successive PM states as shaped by the continuous course of events during a particular match (Briki et al., 2013; Den Hartigh et al., 2014; Gernigon et al., 2010). In one study, Briki et al. (2013) examined cyclists who competed with each other on home trainer bicycles in a (manipulated) race. One competitor started moving toward the defeat, but then gradually progressed toward the victory (positive momentum scenario), whereas the opponent underwent the exact opposite (negative momentum scenario). Briki et al. (2013) found an asymmetrical pattern: The positive change in PM perceptions in the positive momentum scenario was delayed, whereas there was a rapid negative change in PM perceptions in the negative momentum scenario. These results imply that transitions between positive and negative PM are nonlinear, and that a relatively long history of progressing in relation to the victory seems to be needed to enter positive PM, whereas a short history of regressing already triggers negative PM. At the behavioral level, the authors found that exerted efforts decreased quite rapidly when regressing in relation to the victory. Taken together, Briki et al.'s (2013) findings suggest that negative PM is a stronger attractor than positive PM; that is, negative $\mathrm{PM}$ is entered more rapidly and is harder to escape (see also Den Hartigh et al., 2014; Gernigon et al., 2010).

\section{Interconnected Time Scales of Psychological Momentum}

According to complex dynamical systems theorists, a focus on the interconnection between processes that take place at multiple time scales is essential for a clearer understanding of human behavior (e.g., Granic \& Patterson, 2006; Lichtwarck-Aschoff, Van Geert, Bosma, \& Kunnen, 2008; Newell, Liu, \& Mayer-Kress, 2001; Thelen \& Smith, 1994; Van Geert, 2009). In brief, the notion of interconnected time scales refers to the idea that (psychological and behavioral) dynamics in real-time are embedded in a larger process that is shaped across multiple activities. Although researchers have recently approached PM from a dynamical systems perspective, this property of interconnected time scales has never been explicitly addressed in previous PM studies.
To date, theoretical and empirical demonstrations of the interconnection between time scales are primarily found in the domains of cognitive learning (e.g., Steenbeek, Jansen, \& Van Geert, 2012; Van der Steen, Steenbeek, Van Dijk, \& Van Geert, 2014) and motor learning (e.g., Newell et al., 2001; Zanone \& Kelso, 1992). For instance, single learning sessions in a teaching context have been found to shape a child's learning development across successive sessions, which in turn shapes the learning dynamics within (next) sessions (Steenbeek et al., 2012; Van der Steen et al., 2014). Steenbeek et al. (2012) found that a suboptimal session between a teacher and a child (short-term) gives rise to a (problematic) learning trajectory across sessions (long-term), which in turn influences the dynamics between the teacher and child in the next session (short-term), and so forth. In the domain of motor learning, Newell et al. (2001) described how single motor-learning events change the movement repertoire of an individual so that, after some interim period, new movement solutions are available during a next motor-learning event. The theoretical argument for the mechanism underlying interconnected time scales is that repeated events (e.g., performances) change what is called the attractor landscape, that is, the range of stable patterns to which the system may converge (e.g., Granic \& Patterson, 2006; Newell et al., 2001; Thelen \& Smith, 1994; Zanone \& Kelso, 1992).

When the aim is to study interconnected time scales of PM, the first step is to identify different (at least two) time scales. In the literature on developmental processes, the "short-term" time scale is usually defined in terms of real-time activities (e.g., Lewis, 1995; LichtwarckAschoff et al., 2008; Van Geert, 1998). The point where "short-term" changes into "long-term" may seem a fuzzy boundary, at least if we think in terms of duration (a day, week, month, or longer?). However, different time scales can be distinguished when relating them to the different "mechanisms" that govern the processes (e.g., Lichtwarck-Aschoff et al., 2008). Given that the development of PM is inherently related to the goals relative to which an athlete progresses or regresses (e.g., Adler, 1981; Gernigon et al., 2010; Markman \& Guenther, 2007; Vallerand et al., 1988), PM processes would be governed by goal representations at different time scales. This means that the process of within-race PM, such as real-time activities and experiences related to reaching the short-term goal of winning, is embedded in the process of a longer-term PM, such as experiences spanning multiple matches and related to the goal of winning the tournament, which is embedded in an even longer-term PM process, for example related to the goal of winning a seasonal championship spanning multiple tournaments, and so forth (cf. Adler, 1981).

The interconnection between short- and long-term time scales of PM should not be equated with a "carryover effect." This effect implies that accumulated PM during a particular task is maintained for some time, and can thus be carried over to the (start of the) next task (see Markman \& Guenther, 2007). This means that there is a carryover 
of residual PM to another task at the same time scale (i.e., real-time activities and experiences related to accomplishing the task). The notion of interconnected time scales, on the other hand, entails that PM exists (and changes) between multiple time scales. In view of the nature of the processes studied in this article, we define short term as the time scale associated with a within-match goal, long term as the time scale associated with a tournament goal spanning multiple matches, and we expected the PM processes at these two time scales to be interconnected.

Finally, the interconnection of PM processes at different time scales can be linked to the idea of a (changing) PM attractor landscape (cf. Newell et al., 2001). As explained in the previous section, recent research has suggested that negative PM is a relatively strong attractor, which means that this state develops relatively rapidly in athletes (Briki et al., 2013; Den Hartigh et al., 2014; Gernigon et al., 2010). Given the idea that the attractor landscape is shaped by previous experiences or performances (e.g., Granic \& Patterson, 2006; Newell et al., 2001; Zanone \& Kelso, 1992), the PM attractor landscape could take different forms for athletes who have different histories of success and failure in previous races (and thereby have built either long-term positive or negative PM, respectively). More specifically, from a dynamical systems perspective, the degree to which negative PM is a prominent state that can be entered rapidly during a match, would be embedded in (and should not be separated from) the long-term PM process that spans multiple consecutive matches.

\section{The Current Study}

The current study provides the first experimental test of an interconnection between short- and long-term PM. Specifically, we examined (a) whether single performances influence the development of athletes' long-term PM, and importantly (b) whether the athletes' long-term PM feeds into their short-term PM (cf. Newell et al., 2001; Steenbeek et al., 2012). Given that PM embraces a wide range of psychological and behavioral features (e.g., Briki et al., 2012; Gernigon et al., 2010; Taylor \& Demick, 1994), we identified three essential variables describing athletes' PM dynamics. First, at the psychological level, PM was reflected by the direct perception of momentum (i.e., progress in relation to the goal), which is an emergent perception during goal striving (e.g., Briki et al., 2013; Carver \& Scheier, 2002). Second, we focused on another emergent variable during goal striving that is assumed to be related to momentum, namely, self-efficacy (confidence in one's abilities to reach a goal; Bandura, 1997; Shaw, Dzewaltowski, \& McElroy, 1992). Both these psychological variables were thus examined in relation to athletes' long-term (tournament) and short-term (single match) goals. At the behavioral level, we focused on exerted efforts, which have been found to undergo typical changes during positive and negative momentum periods in single matches (Briki et al., 2013; Den Hartigh et al., 2014; Perreault et al., 1998). Hence, changes in perceived momentum, self-efficacy (long-term and short-term) and exerted efforts (short-term) can provide qualitative insights into PM dynamics.

We designed an experiment in which long-term and short-term goals could be defined, the two psychological measures could be collected repeatedly during and across sports matches, and the behavioral measure of effort exertion could be collected while athletes were performing. More specifically, athletes pursued a long-term goal (winning a prize) in a rowing-ergometer tournament, consisting of multiple races in which the athletes were striving for a short-term goal (winning the race). We stated the following two hypotheses.

Hypothesis 1: Races that end in winning or losing lead to the development of positive or negative longterm PM, respectively. This would provide evidence for an influence of the short-term time scale (single performances) on the long-term time scale (longterm tournament PM) (cf. Granic \& Patterson, 2006; Lichtwarck-Aschoff et al., 2008; Newell et al., 2001; Van Geert, 2009).

With regard to the short-term PM dynamics, researchers have found that negative PM develops relatively rapidly, suggesting that negative PM is a temporarily stronger attractor (i.e., more prominent state) than positive PM within the attractor landscape of PM (Briki et al., 2013; Den Hartigh et al., 2014; Gernigon et al., 2010). However, the theory of complex dynamical systems poses that successive real-time events or performances can change the attractor landscape (e.g., Granic \& Patterson, 2006; Newell et al., 2001; Zanone \& Kelso, 1992).

Hypothesis 2: Repeated successful or unsuccessful races affect the PM attractor landscape in a way that, within the next race, the negative PM attractor is weaker for athletes with successful previous performances (i.e., who have developed long-term positive PM), compared with athletes with a history of failure (i.e., who have developed long-term negative PM).

If both hypotheses could be confirmed, this would provide empirical support for an interconnection between short- and long-term PM processes, and thereby deeper insights into the dynamical nature of PM.

\section{Method}

\section{Participants}

We approached male competitive athletes from different sports clubs, and asked whether they would be willing to participate in a rowing-ergometer tournament in which they could win money. Twenty-five athletes, competing at regional $(n=19)$ or national level $(n=6)$, consented to participate. They were active in the following sports: Squash $(n=3)$, basketball $(n=1)$, swimming $(n=6)$, hockey $(n=5)$, speed skating $(n=1)$, floorball $(n=3)$, 
soccer $(n=3)$, and tennis $(n=3)$. The mean age of the participants was 24.05 years $(S D=2.26)$, and on average the participants practiced 4.72 times a week $(S D=4.39)$.

\section{Experimental Setup and Procedure}

The protocol of the study was approved by the Ethical Committee of the Department of Psychology, University of Groningen. We used a comparable setup to the one employed by Den Hartigh et al. (2014), including two rowing ergometers that were placed next to each other. A force sensor (Measurement Specialties, Inc.) was attached between the handle and the chain of each ergometer, and a curtain was placed in between the two ergometers to prevent the participants from being able to see each other during the races. An HD screen was placed on a table in front of the ergometers, serving to broadcast the ongoing race as well as the psychological items that were displayed at repeated intervals during the races. Behind the ergometers was a table with two computers: One computer served to register the data from the force sensor, the other was connected to the HD screen and contained the software used to program the races and display the psychological measures.

The participants successively participated in four sessions at intervals of about one week. The first session was a baseline session, which served to obtain information about the participants' demographics and ergometer performance. Subsequently, participants were assigned to a positive momentum or negative momentum condition, and completed the first race in the second session and the second race in the third session, which they either won (positive momentum condition) or lost (negative momentum condition). Finally, in the third race (fourth session), the participants in the positive momentum and the negative momentum condition were involved in a race that was preprogrammed so that all participants gradually moved from a lead to a defeat (see Table 1). After this fourth session, the participants were debriefed.
First Session (Baseline). The first session was a baseline session that we conducted with each participant individually. Upon his arrival in the experiment room for the first time, the participant signed an informed consent form, a physical health form, and filled out his demographic information. Then, we gave the participant a tour through the experiment room, we demonstrated the devices that enabled us to collect detailed information about his performance (e.g., force sensor), and we explained that we could connect the two ergometers to organize races. Subsequently, the participant did a warm-up on the ergometer for $5 \mathrm{~min}$, after which he did a 1-min, maximum-effort test. During this test we collected the participant's exerted efforts with the force sensor, as well as the distance he rowed according to the performance monitor (PM 4) of the ergometer.

Based on the baseline information, we grouped the participants according to rowing performance and height. This procedure served to organize credible races between competitors of comparable level and stature. In addition, to avoid a priori expectations about the outcome of the race, participants who were from the same sports club were not scheduled to compete against each other, and none of the participants competed against the same opponent twice. The participants were randomly assigned to the positive momentum or negative momentum condition (see Table 1). Finally, three individuals were added as stand-ins (two regular exercisers and one amateur rower) in case gaps appeared in the tournament schedule. These stand-ins were not from the other participants' clubs, they were well trained, and had experience with ergometer rowing. They were available to replace possible dropouts and to show up in case of a late cancellation of a participant before a race (which sometimes occurred in the pilot study). Although there were no unexpected dropouts or late cancellations in the main study, the standins were used in case of incompatible time schedules of participants: In the first two rounds of race sessions three gaps were filled with the stand-ins, and in the last round of sessions two gaps were filled.

Table 1 Race Configurations (8 min Each) of the Positive and Negative Momentum Conditions

\begin{tabular}{|c|c|c|c|c|c|c|c|c|c|c|}
\hline \multirow{2}{*}{$\begin{array}{l}\text { Condition and Race } \\
\text { Race } 1\end{array}$} & \multirow{2}{*}{\multicolumn{2}{|c|}{$\begin{array}{c}\text { Points at } \\
\text { start }\end{array}$}} & \multicolumn{8}{|c|}{ Race configuration per minute } \\
\hline & & & & & & & & & & \\
\hline Positive Momentum & 1 & 0 & 0 & -3 & 0 & +3 & 0 & +3 & +6 & +9 \\
\hline Negative Momentum & 1 & 0 & 0 & +3 & 0 & -3 & 0 & -3 & -6 & -9 \\
\hline \multicolumn{11}{|l|}{ Race 2} \\
\hline Positive Momentum & 2 & +1 & 0 & 0 & +3 & 0 & $-3 / 0$ & +3 & +6 & +9 \\
\hline Negative Momentum & 2 & -1 & 0 & 0 & -3 & 0 & $+3 / 0$ & -3 & -6 & -9 \\
\hline \multicolumn{11}{|l|}{ Race 3} \\
\hline Positive Momentum & 3 & +2 & 0 & +3 & +6 & +3 & $\mathbf{0}$ & -3 & -6 & -9 \\
\hline Negative Momentum & 3 & -2 & 0 & +3 & +6 & +3 & $\mathbf{0}$ & -3 & -6 & -9 \\
\hline
\end{tabular}

Note. Time-gaps in bold correspond to the period in which the short-term PM dynamics were examined. 
Second and Third Sessions (Races 1 and 2). The second and third sessions were two races in which participants directly competed against each other. When participants arrived for their race, they exchanged names and did their warm-up activities. Then, the experimenter provided the instructions. He reminded the participants that they were involved in an ergometer tournament, which had been developed with our unique equipment. We told the participants that they would compete in a maximum of five races. Their goal was to win 3 points, which would mean they would obtain a money prize (we told them that we had 300 euros to distribute among the winners). Winning the first, second or third race resulted in 1 point each, whereas 1 point would be subtracted when losing. We also told them that 2 points could be won or lost in the fourth and fifth race (i.e., in total 4 points could be won or lost in these races). Note that in reality there was no fourth and fifth race, but that we provided this information so that participants in the positive and negative momentum condition would, in theory, both be able to reach the long-term goal in the third race (i.e., the fourth and last session). Thus, the only difference between the conditions was that, before the fourth session, participants in the positive momentum condition had progressed in relation to the long-term goal of winning 3 points and the money prize (having collected +2 points), whereas the participants in the negative condition had regressed (having -2 points).

We informed the participants that they would win the race by taking a 9-s lead on the opponent. Thus, the short-term goal was winning by taking this lead. We told the participants that their performance, which we continuously monitored, was projected on the moving avatars on the screen (a green and an orange rowing boat), so that they could follow the race. In reality, however, the scenarios of the races were programmed beforehand. The first and second races started with a 5-minute period in which the competitors alternated leads of $3 \mathrm{~s}$. Then, between the 5 th and 8 th minute, one of the competitors gradually progressed toward the victory (i.e., a 9-s lead) in steps of $3 \mathrm{~s}$ per minute, whereas the other moved to the defeat (see Table 1). Before the start of each race, we assigned an avatar to each participant by showing a green or orange paper, corresponding to the color of the participant's avatar on the screen (using a colored paper to inform the participant about the color of his avatar was particularly important for the fourth session, see next subsection). Depending on the condition the participant was in, his avatar either won or lost the first and second races (i.e., the second and third sessions).

Furthermore, the experimenter informed the participants that the screen would regularly change to display two questions, and that the race would be displayed again after both participants had answered the questions aloud. To register the item answers, we attached voice recorders to the participants' t-shirts. Moreover, to avoid participants being able to hear each other and be influenced by each other's item answers during the race, they wore soundproof headphones.
Once the participants were ready, the experimenter counted down and launched the race, along with the data collection of the force sensors. Finally, to assess longterm PM, we gave participants a questionnaire before the start of the second race (i.e., third session).

Fourth Session (Race 3) and Debriefing. The fourth session was the last (third) race. Upon their arrival, participants filled out the long-term PM questionnaire again, to examine their long-term PM development (see Hypothesis 1). Subsequently, we gave the instructions. Contrary to the previous two races, in the third race we showed a green paper to both participants before the start (note that the participants did not see the color that was shown to the opponent, because of the curtain that separated them). Doing this, we thus indicated to both participants that their performance was projected on the green avatar (neither of the participants was the orange avatar).

The scenario of the third race followed the methodological guidelines of Haken, Kelso, and Bunz (1985), who stipulated that to test the strength of an attractor, changes in the behavior of a dynamical system (PM in this case) should be studied under the gradual variation of a control parameter that may lead the system to another state. More specifically, during the race, the participant's avatar first moved to a lead of $6 \mathrm{~s}$, after which it gradually moved to a defeat - a lag of $9 \mathrm{~s}$ - in steps of $3 \mathrm{~s}$ per minute. Hence, the position in the race (relative to the victory) was the control parameter here, the gradual variation of which was expected to elicit a change from positive PM to negative PM. The scenario of the third race thus allowed us to test whether the negative PM attractor was weaker for participants in the positive momentum condition than for those in the negative momentum condition (see Hypothesis 2). ${ }^{1}$

After the third race, we gave participants a questionnaire including manipulation checks. After completion, we debriefed the participants about the manipulation of the races and the purpose of the study. In addition, we asked them not to communicate the intention of the study to anybody for one week. In the end, none of the participants suspected that the races were manipulated, which confirms both the credibility of the manipulations and the absence of exchanges of information between participants. Finally, because participants could not actually win money as they thought, we rewarded them with 20 euro (approximately 22.50 US dollars) for their participation.

\section{Measures}

Long-Term Psychological Momentum. Questionnaires were used to assess participants' PM experiences with regard to the long-term (tournament) goal. One item was a direct measure of the perception of momentum, which was adapted from Vallerand et al. (1988): At this moment I am progressing toward winning 3 points and the money prize. This item could be answered from -3 (Not at all) to +3 (Very much). The second item was a 
self-efficacy measure: At this moment, I am confident in my abilities to win 3 points and the money prize, which could be answered from -3 (Not at all confident) to +3 (Very confident). Following Bandura's (2006) guidelines, this item represents the participant's perceived abilities to attain one's goal. Based on the outcomes of our pilot study with competitive athletes, more items were not included, because this could make the participants suspicious (i.e., think they were being psychologically manipulated). In addition, note that the response scales were not the same as the ones traditionally used for momentum and selfefficacy items. The reason for choosing scales ranging from -3 to +3 was to stay consistent with the scales used during the races, and to obtain reliable responses throughout the study (see next subsection).

Short-Term Psychological Momentum. The questionnaire items were adapted so that they pertained to the short-term goal of the race. The items were as follows: Now, at this moment . . . I am progressing toward the victory (perception of momentum; $-3=$ Not at all, $+3=$ Very much), and Now, at this moment, I am confident in my abilities to win this race (self-efficacy; $-3=$ Not at all confident,$+3=$ Very confident) . These questions appeared each minute during the race (i.e., $15 \mathrm{~s}$ after each change in time gap between the avatars). The choices for only two items and a response scale from -3 to +3 , solved the issue that the experiment would be too cognitively demanding and that we would obtain less reliable item answers. In the pilot studies, athletes had difficulties providing accurate responses when being exposed to more than two questions and to response scales ranging from 1 to 7 or 9 .

Furthermore, exerted efforts were registered with the force sensors that were attached between the handles and chains of the ergometers. We collected the force data in units of volts in Matlab, at a frequency of $100 \mathrm{~Hz}$. Subsequently, we transformed the data into newtons according to a linear transformation provided by the manufacturer of the sensors. Given the continuous nature of the forcesensor measures, we divided the data into five sections before the analysis, corresponding to the periods in which there was a specific time gap between the avatars on the screen. Hence, as for the perceptions of momentum and self-efficacy, we had one measure of efforts for each time gap between the avatars. Moreover, to allow reliable comparisons, each participant's effort exertion was calculated relative to his average output during the 1-min maximum-effort test in the baseline session.

\section{Analysis}

To examine the influence of the single races on participants' long-term PM development (Hypothesis 1), and how this feeds into the short-term PM dynamics in the third race (see Hypothesis 2), we used Monte Carlo permutation tests. The Monte Carlo test determines the probability that the observed result is caused by chance alone, by simulating that chance. This is based on a repeated shuffling of the collected data (i.e., 10,000 times across participants or time gaps, depending on the type of question), and a calculation of the probability that the same, or more extreme, result can be found by chance. Applying Monte Carlo permutation tests was particularly suitable for the current study, because relative to traditional parametric (e.g., ANOVA) and nonparametric tests (e.g., Kruskal-Wallis), Monte Carlo tests are more appropriate in the case of relatively small sample sizes and are well suited to study patterns of change (e.g., Manly, 1997; Todman \& Dugard, 2001; Van Geert, Steenbeek, \& Kunnen, 2012). Furthermore, the Monte Carlo procedure allowed tests of interactions between "time" and "condition." For instance, with regard to short-term PM, it is possible to test what the probability is that differences across time gaps between conditions are the same as, or stronger than, the observed differences, given the null-hypothesis that changes in PM measures across time-gaps are independent of the condition. Finally, to provide a measure for the magnitude of our results, we calculated Cohen's $d$.

\section{Results}

\section{Preliminary Analyses}

Of the 25 competitive athletes, three were not taken into account for the analysis. One participant incurred an (soccer) injury before the fourth session (i.e., third race). Another participant could not finish the fourth session; his race was suspended because his opponent stopped rowing before the end of the race (this opponent was one of the stand-ins). Finally, one participant did not provide item responses reflecting his momentum and self-efficacy perceptions during the fourth session. Of the remaining 22 participants who finished the study, 11 were in the positive momentum condition and 11 in the negative momentum condition. Before running the main analyses, we used the Monte Carlo procedure to test whether participants in the two conditions differed on variables that may influence our results: Height, hours of practice per week, number of meters in the baseline session, and exerted efforts in the 1-min maximal-test. No significant differences were found on any of these variables $(p s>.30)$.

\section{Long-Term Psychological Momentum}

To determine the influence of single performances on the long-term PM development, we conducted two tests. First, we compared the participants in the positive and negative momentum conditions at their levels of perceived momentum and self-efficacy before race 2 (i.e., after a victory or defeat in the first race) and before race 3 (i.e., after two victories or defeats). The results are displayed in Figure 1. Monte Carlo permutation tests revealed that the momentum perception before race 2 was higher for participants in the positive momentum condition $(M=.64, S D=.50)$ than for those in the negative momentum condition $(M=-.73, S D=.90 ; p<.001, d=$ 1.86). Before the third race, the momentum perception 
was also higher in the positive momentum condition $(M=1.18, S D=.75)$ than in the negative condition $(M$ $=-1.91, S D=.94 ; p<.001, d=3.62)$. With regard to self-efficacy, measured before race 2 , the participants in the positive momentum condition scored higher $(M=.45$, $S D=.82)$ than those in the negative momentum condition $(M=-.45, S D=1.21 ; p=.03, d=.88)$. Before the third race, participants' self-efficacy was also higher in the positive momentum condition $(M=1.18, S D=.75)$ than in the negative condition $(M=-1.55, S D=1.13 ; p$ $<.001, d=2.85)$.

Second, we tested whether perceived (long-term) momentum and self-efficacy changed from the first time point we assessed (before race 2) to the second time point (before race 3 ). The change (i.e., increase) in the perception of momentum approached significance for the participants in the positive momentum condition $(p=.06$, $d=.85)$, whereas the momentum perception significantly decreased for those in the negative momentum condition ( $p=.007, d=1.28)$. Furthermore, participants' selfefficacy significantly increased in the positive momentum condition ( $p=.04, d=.92)$ and significantly decreased in the negative momentum condition $(p=.03, d=.93)$. Taken together, these results provide converging evidence for Hypothesis 1 that races that end in winning or losing lead to the development of positive or negative long-term $\mathrm{PM}$, respectively.

\section{Short-Term Psychological Momentum}

The short-term PM dynamics were examined in the third race when the participants were regressing from a lead of $6 \mathrm{~s}$-close to victory-to a lag of $6 \mathrm{~s}$-close to defeat. The dynamics of perceived momentum, self-efficacy, and exerted efforts are displayed in Figure 2. We conducted two tests to determine whether the participants'

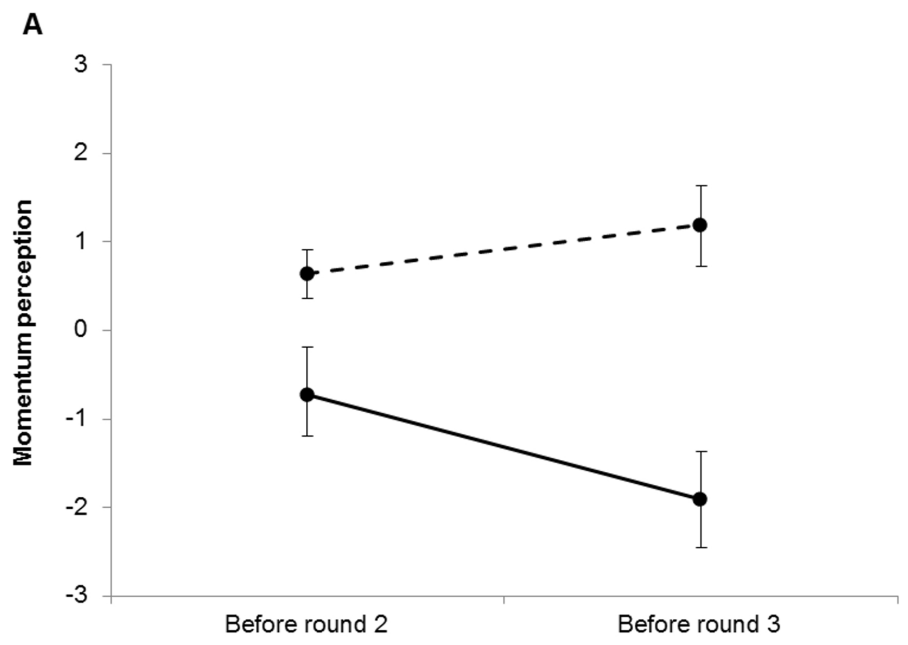

B

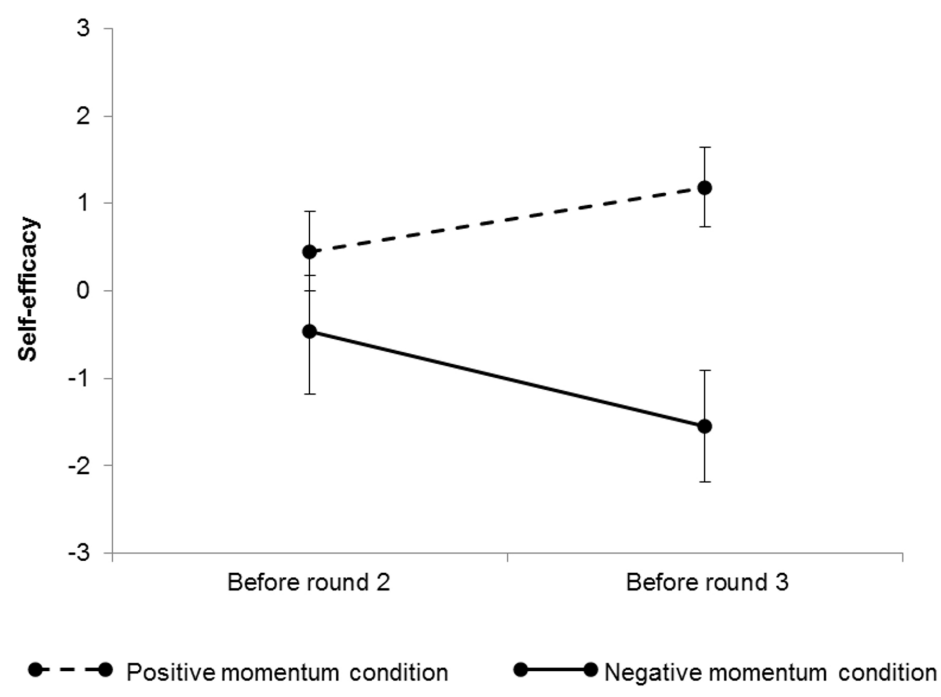

Figure 1 - Long-term results of momentum perception (A) and self-efficacy (B) for the positive momentum condition and the negative momentum condition. The error bars correspond to simulated $95 \%$ confidence intervals based on 10,000 resamplings of the data. 
long-term PM fed into their short-term PM. First, we compared the participants in the positive momentum and negative momentum conditions on their average values of perceived momentum, self-efficacy, and exerted efforts. Results show that participants in the positive momentum condition had higher momentum perceptions $(M=.45$, $S D=.69)$ than those in the negative momentum condition $(M=-.65, S D=.65 ; p<.001, d=1.66)$. Furthermore, self-efficacy was higher in the positive momentum condition $(M=.31, S D=.65)$ than in the negative momentum condition $(M=-.58, S D=.53 ; p<.001, d=1.50)$. For these two variables, significant differences between the conditions $(p<.05)$ were located at time gaps $0,-3$, and -6 s. Finally, the relative efforts were higher in the positive momentum condition $(M=71.87 \%, S D=$ 4.51) than in the negative momentum condition $(M=$ $67.73 \%, S D=6.69, p=.05, d=.73)$. Significant differences between conditions $(p<.05)$ were located at time gaps -3 and -6 s.

Second, we tested differences between participants in the positive and negative momentum conditions in terms of the rates of decrease in perceived momentum,

A

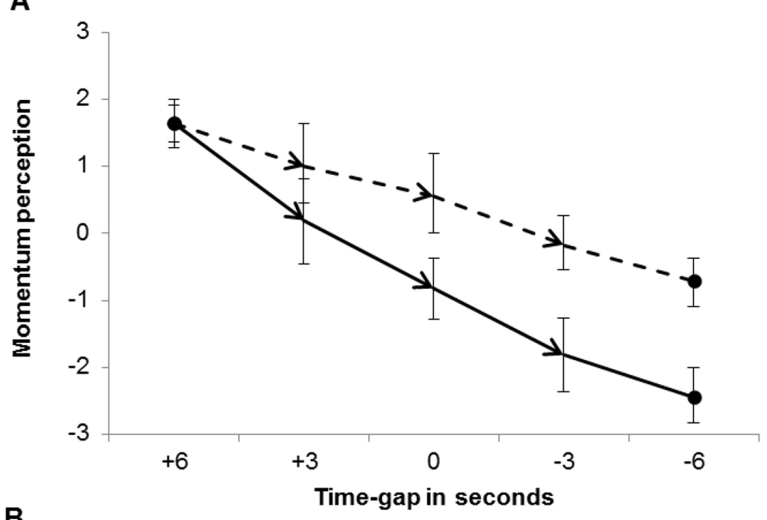

B

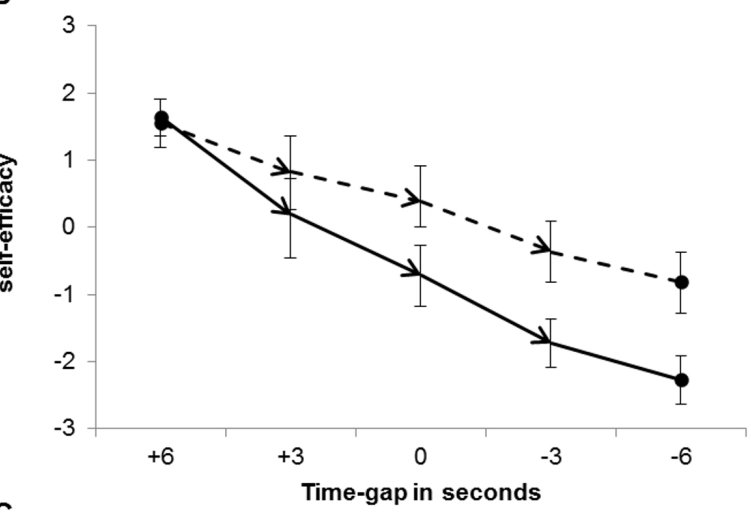

C

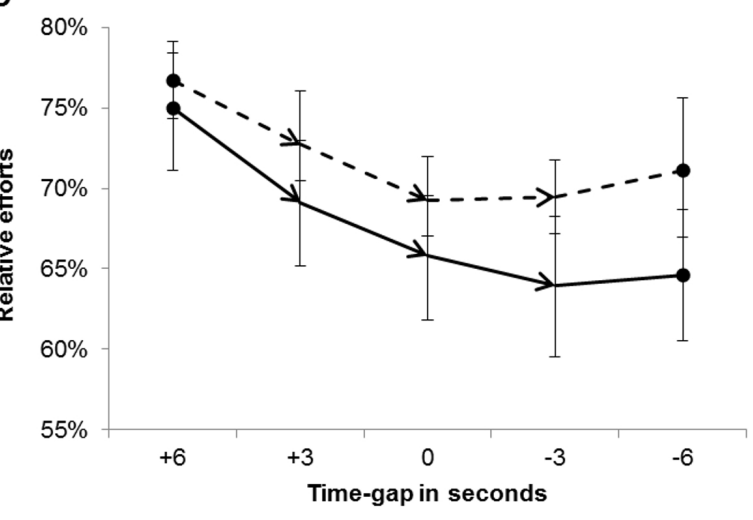

$--\rightarrow$ Positive momentum condition $\longrightarrow$ Negative momentum condition

Figure 2 - Short-term results of momentum perception (A), self-efficacy (B), and exerted efforts (C) according to time-gap and experimental condition. The error bars correspond to simulated $95 \%$ confidence intervals based on 10,000 resamplings of the data. 
self-efficacy, and exerted efforts, from the beginning of the negative momentum manipulation $(+6 \mathrm{~s})$ until the end ( $-6 \mathrm{~s}$ ). Monte Carlo permutation tests revealed that the decrease in perceived momentum was significantly less steep (i.e., less rapid) in the positive momentum condition $\left(M_{\text {decrease }}=-2.36\right)$ than in the negative momentum condition $\left(M_{\text {decrease }}=-4.09 ; p<.001, d=2.11\right)$. Furthermore, the decrease in self-efficacy was less steep in the positive momentum condition $\left(M_{\text {decrease }}=-2.36\right)$ than in the negative momentum condition $\left(M_{\text {decrease }}=-3.91 ; p<.001, d\right.$ $=1.65)$. The decrease in efforts was not significantly less steep for the participants in the positive momentum condition $(p=.12)$. Together, these results provide support for Hypothesis 2 that the negative PM attractor is weaker (i.e., less prominent) for athletes who have developed long-term positive PM, compared with those who have developed long-term negative PM. ${ }^{2}$

\section{Discussion}

Recently, researchers started viewing PM as a complex dynamical system and found that athletes' PM may develop nonlinearly, depending on the ongoing history of events during a particular match (Briki et al., 2013; Den Hartigh et al., 2014; Gernigon et al., 2010). More specifically, recent studies showed that, within a single sports match, a state of negative PM develops rapidly, whereas positive PM develops after a relatively long history of positive events (e.g., winning seconds on the opponent). This suggests that negative PM is a stronger attractor than positive PM (Briki et al., 2013; Den Hartigh et al., 2014). Although previous studies have improved the understanding of PM dynamics, one defining dynamical property, namely interconnected time scales (i.e., the connection between long- and short-term PM processes), has remained untested. This property entails that the strength of the (within-match) negative PM attractor would be related to previous performances that have shaped the long-term PM process across multiple matches.

To experimentally test the property of interconnected time scales, we first examined whether single performances affect athletes' long-term PM experiences. Compared with participants in the negative momentum condition who successively lost races in a rowing ergometer tournament, the participants in the positive momentum condition had higher perceptions of momentum and self-efficacy, before both the second and third race (i.e., after having won the first and second race). This finding is in line with the suggestion that PM may develop across successive matches (Adler, 1981). We also found increases and decreases in perceptions of momentum and self-efficacy in the positive and negative momentum condition, respectively. Although these results may be intuitive, given the knowledge that both momentum perceptions (e.g., Adler, 1981; Moesch \& Apitzsch, 2012; Taylor \& Demick, 1994) and self-efficacy (Bandura, 1997; Gernigon \& Delloye, 2003) are related to success and failure, it is interesting to note that the changes in these variables were more prominent in the negative momentum condition. This suggests that negative PM may not only be triggered more easily during a single sports match (Briki et al., 2013; Den Hartigh et al., 2014; Gernigon et al., 2010), but also across a series of matches.

Thus, in accordance with our first expectation, a series of races that end in winning or losing leads to the development of positive or negative long-term PM, respectively. We next examined the key question whether the long-term PM that athletes developed over the course of multiple races feeds into the athletes' short-term PM (i.e., the psychological and behavioral dynamics within the subsequent (third) race). We found strong evidence that perceptions of momentum and self-efficacy were higher when participants had developed long-term positive PM than when they had developed long-term negative PM. In addition, we found a significant effect, with a moderate to strong effect size (see Cohen, 1988), for our behavioral measure. That is, relative to athletes who had developed long-term negative PM, exerted efforts were higher for athletes who had developed long-term positive PM. Finally, perceptions of momentum and selfefficacy evidently changed (decreased) less rapidly when participants had a history of successful races. These findings show that participants who had developed long-term positive PM were less sensitive to the gradual regression within the race, than participants who had developed long-term negative PM. This suggests that a series of previous successful or unsuccessful races changed the PM attractor landscape for subsequent races (cf. Granic \& Patterson, 2006; Newell et al., 2001; Thelen \& Smith, 1994; Zanone \& Kelso, 1992). As anticipated, our results indicate that the negative PM attractor was weaker for athletes with a history of successful races.

Given that we found (a) that single performances influence the development of athletes' long-term PM, and importantly (b) that the athletes' long-term PM feeds into their short-term PM, we may conclude that short- and long-term PM are interconnected processes. The finding that PM is a dynamical phenomenon spanning multiple interconnected time scales, underscores the relevance of applying a complex dynamical systems perspective to the study of sport performance processes (e.g., Davids et al., 2014; Den Hartigh, Cox, Gernigon, Van Yperen, \& Van Geert, 2015), and of PM in particular (Gernigon et al., 2010). A possible limitation of our experiment, however, is that our sample size was relatively small, which was due to the labor-intensive nature of the study and to the constraints of the tournament schedule. To account for this, we used statistical analyses that are highly suited when dealing with smaller sample sizes (i.e., Monte Carlo permutation tests). The credibility of our results is further strengthened by the generally large effect sizes (Cohen, 1988). Nevertheless, this first study on the interconnection between PM time scales should be replicated and extended to provide additional evidence. As in the current research, in future studies with competitive athletes PM should be tracked across time while manipulating, or monitoring, the goal progress at different time scales. 
A second limitation may be that our study did not involve a control group that neither won nor lost the first two races. Because one of the primary foci of this study was how the long-term process feeds into the short-term (PM) process, we decided to make two experimental groups that were exposed to opposite (positive versus negative momentum) scenarios in the first two races, and to the same scenario in the last race. In future studies conducted in a setting that allows the recruitment of more participants, researchers may decide to add a control group. Besides, because PM dynamics are assumed to be related to physiological changes (cf. Gernigon et al., 2010; Taylor \& Demick, 1994), experimental studies on PM may be extended by collecting physiological data.

In conclusion, while earlier studies examined PM during a single match, and demonstrated that PM is dependent on the history of events within one match (Briki et al., 2013; Den Hartigh et al., 2014; Gernigon et al., 2010), we propose that the history-dependent nature of PM extends across multiple matches. This means that athletes' tendency to enter a positive or negative PM in a match, and hence their positive or negative PM attractor strength, depends on the ongoing scenario of the match and is formed by a long-term PM process that has developed out of previous performances. For future research, it would be interesting to explore whether the interconnection of time scales extends to even longer time scales, such as an entire sports season. One possibility could be to study the performance patterns of athletes during matches, tournaments, and over the course of multiple months (cf. Minbashian \& Luppino, 2014). Another interesting avenue would be to explore how variations in intervals between (successful and unsuccessful) matches have an impact on the long-term PM development and the within-match PM dynamics. According to the theory of complex dynamical systems, when perturbations are applied at longer or shorter intervals, the system has more or less time to recover, respectively (Kelso, 1995). In the case of PM this would mean, for instance, that when repeatedly losing matches with only a few days in between (as opposed to approximately a week), athletes' negative PM attractor may be temporarily stronger, and athletes may therefore enter negative PM even more rapidly during a match (and the opposite after a series of victories). From a practical perspective, our findings indicate that coaches should be aware that athletes' psychological states and actions are not just influenced by momentary positive or negative events, but are shaped by a larger performance process that unfolds during, and extends across, sports matches.

\section{Notes}

1. The exact opposite scenario-a scenario in which the athletes progressed from a lag of $6 \mathrm{~s}$ to a victory-could not be added in this experimental setup for different experimental and practical reasons. From a practical standpoint, for instance, athletes congratulated and thanked each other after each race; therefore, we had only one opportunity to deceive the participants regarding the color of their (green) avatar.

2. For each result, based on the Monte Carlo procedure, we directly tested the effects in the hypothesized direction. An ANOVA repeated measures procedure revealed similar significant results. Only the time gap $\times$ momentum condition interaction effect for exerted efforts revealed a $p$-value above the alpha-level of .05 when using the ANOVA repeated measures procedure (i.e., $p=.09$ with Greenhouse-Geisser correction), which is in line with the reported Monte Carlo result that the decrease of efforts for the positive momentum group did not significantly differ from the decrease in the negative momentum condition $(p=.12)$.

\section{References}

Adler, P. (1981). Momentum: A theory of social action. Beverly Hills, CA: Sage.

Adler, P., \& Adler, P.A. (1978). The role of momentum in sport. Urban Life, 7, 153-175.

Bandura, A. (1997). Self-efficacy: The exercise of control. New York: Freeman.

Bandura, A. (2006). Guide for creating self-efficacy scales. In F. Pajares \& T. Urdan (Eds.), Self-efficacy beliefs of adolescents (pp. 307-337). Greenwich: Information Age Publishing.

Briki, W., Den Hartigh, R.J.R., Hauw, D., \& Gernigon, C. (2012). A qualitative exploration of the psychological contents and dynamics of momentum in sport. International Journal of Sport Psychology, 43, 365-384. doi:10.7352/ IJSP2012.43.365

Briki, W., Den Hartigh, R.J.R., Markman, K.D., \& Gernigon, C. (2014). How do sport supporters experience positive and negative psychological momentum changes during a simulated cycling competition? Psychology of Sport and Exercise, 15, 216-221. doi:10.1016/j.psychsport.2013.11.006

Briki, W., Den Hartigh, R.J.R., Markman, K.D., Micallef, J-P., \& Gernigon, C. (2013). How psychological momentum changes in athletes during a sport competition. Psychology of Sport and Exercise, 14, 389-396. doi:10.1016/j. psychsport.2012.11.009

Briki, W., Doron, J., Markman, K.D., Den Hartigh, R.J.R., \& Gernigon, C. (2014). Differential reactions of actors and observers to the triggering and interruption of psychological momentum. Motivation and Emotion, 38, 263-269. doi:10.1007/s11031-013-9372-3

Carver, C.S., \& Scheier, M.F. (2002). Control processes and self-organization as complementary principles underlying behavior. Personality and Social Psychology Review, 6, 304-315. doi:10.1207/S15327957PSPR0604_05

Cohen, J. (1988). Statistical power analysis for the behavioral sciences (2nd ed.). Hillsdale, NJ: Lawrence Erlbaum Associates.

Davids, K., Hristoviski, R., Araújo, D., Balaque-Serre, N., Button, C., \& Passos, P. (2014). Complex systems in sport. London: Routledge.

Den Hartigh, R.J.R., Cox, R.F.A., Gernigon, C., Van Yperen, N.W., \& Van Geert, P.L.C. (2015). Pink noise in rowing ergometer performance and the role of skill level. Motor Control, 19, 355-369. PubMed doi:10.1123/mc.2014-0071 
Den Hartigh, R.J.R., Gernigon, C., Van Yperen, N.W., Marin, L., \& Van Geert, P.L.C. (2014). How psychological and behavioral team states change during positive and negative momentum. PLoS One, 9(5), e97887. PubMed doi:10.1371/journal.pone.0097887

Eisler, L., \& Spink, K.S. (1998). Effects of scoring configuration and task cohesion on the perception of psychological momentum. Journal of Sport \& Exercise Psychology, 20, 311-320.

Gernigon, C., Briki, W., \& Eykens, K. (2010). The dynamics of psychological momentum in sport: The role of ongoing history of performance patterns. Journal of Sport \& Exercise Psychology, 32, 377-400. PubMed

Gernigon, C., \& Delloye, J.B. (2003). Self-efficacy, causal attribution, and track athletic performance following unexpected success or failure among elite sprinters. The Sport Psychologist, 17, 55-76.

Granic, I., \& Patterson, G.R. (2006). Toward a comprehensive model of antisocial development: a dynamic systems approach. Psychological Review, 113, 101-131. PubMed doi:10.1037/0033-295X.113.1.101

Haken, H., Kelso, J.A.S., \& Bunz, H. (1985). A theoretical model of phase transitions in human hand movements. Biological Cybernetics, 51, 347-356. PubMed doi:10.1007/ BF00336922

Iso-Ahola, S.E., \& Dotson, C.O. (2014). Psychological momentum: Why success breeds success. Review of General Psychology, 18, 19-33. doi:10.1037/a0036406

Jones, M.I., \& Harwood, C. (2008). Psychological momentum within competitive soccer: players' perspectives. Journal of Applied Sport Psychology, 20, 57-72. doi:10.1080/10413200701784841

Kelso, J.A.S. (1995). Dynamic patterns: The self-organization of brain and behavior. Cambridge, MA: MIT Press.

Lewis, M.D. (1995). Cognition-emotion feedback and the self-organization of developmental paths. Human Development, 38, 71-102. doi:10.1159/000278302

Lichtwarck-Aschoff, A., van Geert, P., Bosma, H., \& Kunnen, S. (2008). Time and identity: A framework for research and theory formation. Developmental Review, 28, 370-400. doi:10.1016/j.dr.2008.04.001

Manly, B.F.J. (1997). Randomization bootstrap and Monte Carlo methods in biology (2nd ed.). Boca Raton, FL: Chapman \& Hall.

Markman, K.D., \& Guenther, C.L. (2007). Psychological momentum: Intuitive physics and naive beliefs. Personality and Social Psychology Bulletin, 33, 800-812. PubMed doi:10.1177/0146167207301026

Miller, S., \& Weinberg, R.S. (1991). Perceptions of psychological momentum and their relationship to performance. The Sport Psychologist, 5, 211-222.

Minbashian, A., \& Luppino, D. (2014). Short-term and longterm within-person variability in performance: An integrative model. The Journal of Applied Psychology, 99, 898-914. PubMed doi:10.1037/a0037402

Moesch, K., \& Apitzsch, E. (2012). How do coaches experience psychological momentum? A qualitative study of female elite handball teams. The Sport Psychologist, 26, 435-453.
Newell, K.M., Liu, Y.T., \& Mayer-Kress, G. (2001). Time scales in motor learning and development. Psychological Review, 108, 57-82. PubMed doi:10.1037/0033-295X.108.1.57

Nowak, A., \& Vallacher, R.R. (1998). Dynamical social psychology. New York: Guilford Press.

Perreault, S., Vallerand, R.J., Montgomery, D., \& Provencher, P. (1998). Coming from behind: On the effect of psychological momentum on sport performance. Journal of Sport \& Exercise Psychology, 20, 421-436.

Shaw, J.M., Dzewaltowski, D.A., \& McElroy, M. (1992). Selfefficacy and causal attributions as mediators of perceptions of psychological momentum. Journal of Sport \& Exercise Psychology, 14, 134-147.

Steenbeek, H., Jansen, L., \& van Geert, P. (2012). Scaffolding dynamics and the emergence of problematic learning trajectories. Learning and Individual Differences, 22, 64-75. doi:10.1016/j.lindif.2011.11.014

Taylor, J., \& Demick, A. (1994). A multidimensional model of momentum in sports. Journal of Applied Sport Psychology, 6, 51-70. doi:10.1080/10413209408406465

Thelen, E., \& Smith, L.B. (1994). A dynamic systems approach to the development of cognition and action. Cambridge, MA: MIT Press.

Todman, J.B., \& Dugard, P. (2001). Single-case and small-n experimental designs: A practical guide to randomization tests. Mahwah, NJ: Erlbaum.

Vallerand, R.J., Colavecchio, P.G., \& Pelletier, L.G. (1988). Psychological momentum and performance inferences: A preliminary test of the antecedents-consequences psychological momentum model. Journal of Sport \& Exercise Psychology, 10, 92-108.

Van Der Steen, S., Steenbeek, H., Van Dijk, M., \& Van Geert, P. (2014). A process approach to children's understanding of scientific concepts: A longitudinal case study. Learning and Individual Differences, 30, 84-91. doi:10.1016/j. lindif.2013.12.004

Van Geert, P. (1994). Dynamic systems of development. Change between complexity and chaos. New York: Harvester.

Van Geert, P. (1998). A dynamic systems model of basic developmental mechanisms: Piaget, Vygotsky, and beyond. Psychological Review, 105, 634-677. doi:10.1037/0033295X.105.4.634-677

Van Geert, P. (2009). Complex dynamic systems of development. In R.A. Meyers (Ed.), Encyclopedia of complexity and system science (pp. 1872-1916). New York: Springer. doi:10.1007/978-0-387-30440-3_120

Van Geert, P., Steenbeek, H., \& Kunnen, S. (2012). Monte Carlo techniques: Statistical simulation for developmental data. In S. Kunnen (Ed.), A dynamical systems approach to adolescent development (pp. 43-53). Hove: Psychology Press.

Zanone, P.G., \& Kelso, J.A.S. (1992). Evolution of behavioral attractors with learning: Nonequilibrium phase transitions. Journal of Experimental Psychology. Human Perception and Performance, 18, 403-421. PubMed doi:10.1037/0096-1523.18.2.403

Manuscript submitted: June 13, 2015

Revision accepted: December 19, 2015 